\title{
Features of urban facilities transformation during territory reconstruction
}

\author{
Alexandra Vorobyeva ${ }^{1, *}$ \\ ${ }^{1}$ School of architecture, design and arts DSTU, Petrovskaya st., 49, Rostov-on-Don, 344010, Russia
}

\begin{abstract}
The article deals with the issues of reconstruction of cities in time and space. The analysis of the transformation of urban areas of European countries in the previous centuries was carried out, which made it possible to identify the main modern principles of the transformation of urban objects.
\end{abstract}

\section{Introduction}

Cities are constantly transforming and changing as a result of the development of socioeconomic conditions, population growth, changes in the needs of residents, wear and tear of material resources, the emergence of new technologies, etc. The processes taking place in the urban environment constantly lead to the transformation of not only individual territories, but also urban objects of various functional purposes. Currently, in connection with the significant growth of urban areas, the issues of transforming urban areas are of particular relevance. Restraining the growth of cities, the emergence of transport problems, the inconsistency of the architectural and spatial parameters of the city and its development with modern requirements requires a set of measures for the reconstruction of territories [1-4].

\section{Historical experience of transformation of territories}

Historical experience shows that similar problems arose in European states during the modernization of medieval cities. For example, urban planning work in Paris, carried out under the leadership of Baron Haussmann at the end of the 18th century, is known. Occupying the post of prefect of the Seine department, Haussmann founded the Commission of Artists. Its task was to develop projects for the placement of new streets and boulevards in the city, which actually changed the layout of residential areas. The streets of Rivoli along the Tuileries Gardens, Boulevard Richard-Lenoir, Boulevard Haussmann and others created in that historical period still define the planning structure of the center of Paris. It should be noted that the more successful the city planners identified the natural features of the place and included in the urban fabric, the more expressive and picturesque the city itself became [5-7]. Further reconstruction of the city's territory while preserving the features of the landscape creates its unique image and will be remembered forever. For example, during the reconstruction of the city center of Vilnius (Lithuania), the green spaces of the natural Castle

\footnotetext{
* Corresponding author: rostland@mail.ru
} 
Hill were preserved with the construction of the Gediminas Tower. The natural park created here is still an associative image of the city today.

\section{Reconstruction of urban areas in the XX-th century}

It should be noted that the reconstruction of the territories of large urban formations took place in many countries. However, most of them have their own characteristics. The French "Architectural School", after the construction of the country's first 59-storey tower "Montparnasse" with a height of 210 meters in 1973, for many years abandoned the construction of high-rise buildings in the historic center of Paris.
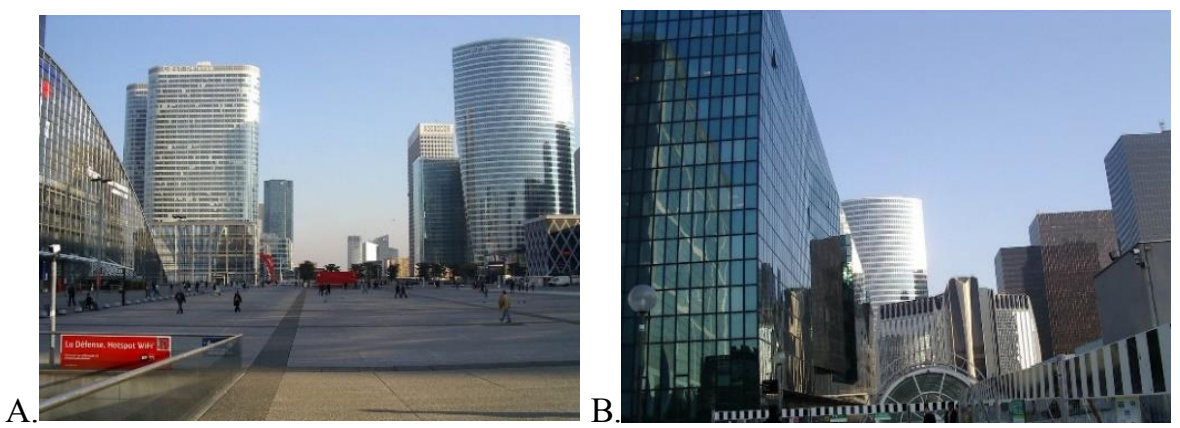

Fig. 1. District of La Defense in Paris State of the art. Photo by the author. Where: A. General view of an artificial platform with high-rise buildings; B. Development of the Defense district with administrative and commercial buildings.

City planners have legislated this decision since 1977 in order to preserve the unique historical environment of the city of Paris.

The construction of new high-rise buildings in Paris (France) has been authorized in modern business and residential areas of the suburbs of Paris. The first of these was the La Defense district, which is the largest business center in Europe. It has about 45 buildings, the height of which reaches more than 90 meters (Fig. 1). In the early 2000s, the City of Paris initiated the grandiose urban development project of the ZAC Batignolles. Together with NCFR (National Company of French Railways) and FRN (French Railways Network), they entered into an agreement providing financial and technical conditions for the reconstruction of 54 hectares of railway and logistics facilities of the former cargo station of the French railway company NCFR. The new renovation project for the Clichy district of Batinolle in the 17th arrondissement of Paris is one of the eco-districts in which the city is pursuing an ambitious sustainable development policy. The residential area of Clichy Batinolle includes the development of several neighborhoods with residential buildings up to 50 meters high. The new Palace of Justice by architect Renzo Piano, 160 meters high, was built here.

The architectural and planning structure of the city that took shape in time is based on the rational organization of the territory with its own transport infrastructure. The outline of the quarters of the city education center is often a monument of urban planning art and is protected by the state. When carrying out reconstruction measures, it will be necessary to search for individual solutions to functional tasks and transport problems. In such areas, along with the requirement to ensure the convenience of transport services, one of the direction of reconstruction measures will be to preserve the existing planning grid of streets and its spatial characteristics. This will allow preserving both the historically established planning system of streets and roads and their environmental characteristics.

It is important to preserve and restore historical squares and pedestrian streets in areas with valuable buildings [8]. To ensure the required frequency of the backbone network and 
its capacity without resorting to the expansion of existing streets, it is advisable (in some cases) to organize one-way traffic. To preserve the spatial characteristics on such streets, traffic intersections are solved at the same level. Historical experience shows that the image of a city is remembered forever in the case when all its elements represent a single artistic whole, including the natural basis of the territory [9].

\section{Modern principles of transforming urban objects}

The experience of reconstruction of urban formations in European countries shows that in many cases the principle of preserving the creative urban planning heritage is observed. This principle determines the mandatory selection of only those methods of planning and spatial organization of the urban environment that meet the modern requirements for the formation of a comfortable environment in the city and do not contradict the social programs of the city's development. Practice shows that in the historical parts of the city, an element of the planning structure of the city is a quarter with a perimeter development of residential buildings. And it was the quarter that was the primary planning unit.

Widespread in the 20 s of the twentieth century. the so-called principle of "free" development (architects Le Corbusier, Thomas Adams, Clarence Arthur Perry) made it possible to transform the historic quarter into a microdistrict. In the microdistrict, a freely organized group development was carried out with its own courtyard and a system of cultural and consumer services. The ideal scheme of the urban microdistrict was taken up and reworked in many countries of the world. In our country, in Soviet times, the microdistrict was the main method of organizing the residential area. And the inclusion of public buildings in it determined the expansion of the area. In the Soviet period, in a residential area, which was the main structural element in the development of a residential area planning project, the size of a microdistrict could be about 80 hectares. In the structure of a residential area, the number of microdistricts and their sizes were determined by the peculiarities of the natural landscape, lighting conditions and norms of transport accessibility [10-11]. The population of the microdistricts was provided with objects of daily service, taking into account the normative accessibility.

In developing cities, the nature of the structural organization of residential areas in the central part and in the periphery is due to the temporal factor of their organization. For the central regions of such cities, as a rule, mainly small building blocks are characteristic. Here, street, courtyard and inner-quarter spaces play a great role in the life of a city dweller [1213]. The existing service network is characterized by the absence of a clearly expressed hierarchy in its spatial construction.

There are a number of European countries that have adopted the transformation of urban areas on the "island" principle. For example, in Milan (Italy) a competition was announced for a project for the reconstruction of the territory, which in 1920 was set aside on the outskirts of the city for the organization of a trade fair. The competition was attended by world-class architects such as Zaha Hadid, Arata Isozaki, Daniel Libeskind, Andrea Maffei, Katherine Gustafson and others. All projected objects on the territory are included and united by a green area (Fig. 2). Its area is about half of the entire territory.

The design of the park was developed by the design bureau Catherine Gustafson, which, according to the plan of the designers, should be a "microcosm" of the landscape of the Milan region. Part of the territory is a "Garden in a garden". Here the "Garden of Butterflies", "Garden of Sculpture", "Garden of the Foothills of the Alps", "Plains Garden", as well as themed groves of pines, oaks, beech, maples, etc. are created. [14].

The central place in the reconstructed area is occupied by an area with three skyscrapers, projects of which belong to three architects - Zaha Hadid, Arata Isozaki and Daniel Libeskind (218, 185 and 170 meters high). Each of the towers has its own shape. The Arata Isozaki 
Tower is designed in a traditional rectangular shape. The Zaha Hadid tower has a sail shape. Daniel Libesktnd designed the tower as a coiling spiral. Construction and further management will be carried out by the Generali Group with the CityLife project.

The towers include office space, shopping malls, restaurants, service facilities, and underground car parks. The territory itself has been declared pedestrian. There is also a dedicated area for cyclists and electric vehicles. The parking lots can be accessed by the underground road system.

In the southern part of the territory there are two residential areas designed by Daniel Libeskind and Zaha Hadid (Fig. 3, Fig. 4).

Libeskind designed a residential area formed by five buildings with their own courtyard. Under the buildings, underground parking lots are organized, the entrances to which are carried out along a circular ramp isolated from pedestrians. The entire courtyard is given over to the residents of the quarter. It is organized in the form of a mound. On it there is an alternation of open and closed spaces in the form of a natural lawn and plantings of decorative trees.

The buildings have vertical wooden slats on asymmetrical balconies. Decorating buildings with frames designed by Libeskind allows you to freely fit modern architecture into the historical context of the place. And their asymmetrical design emphasizes the faceted and elongated shapes of the buildings. At the same time, wooden slats perform a sun protection function like blinds.

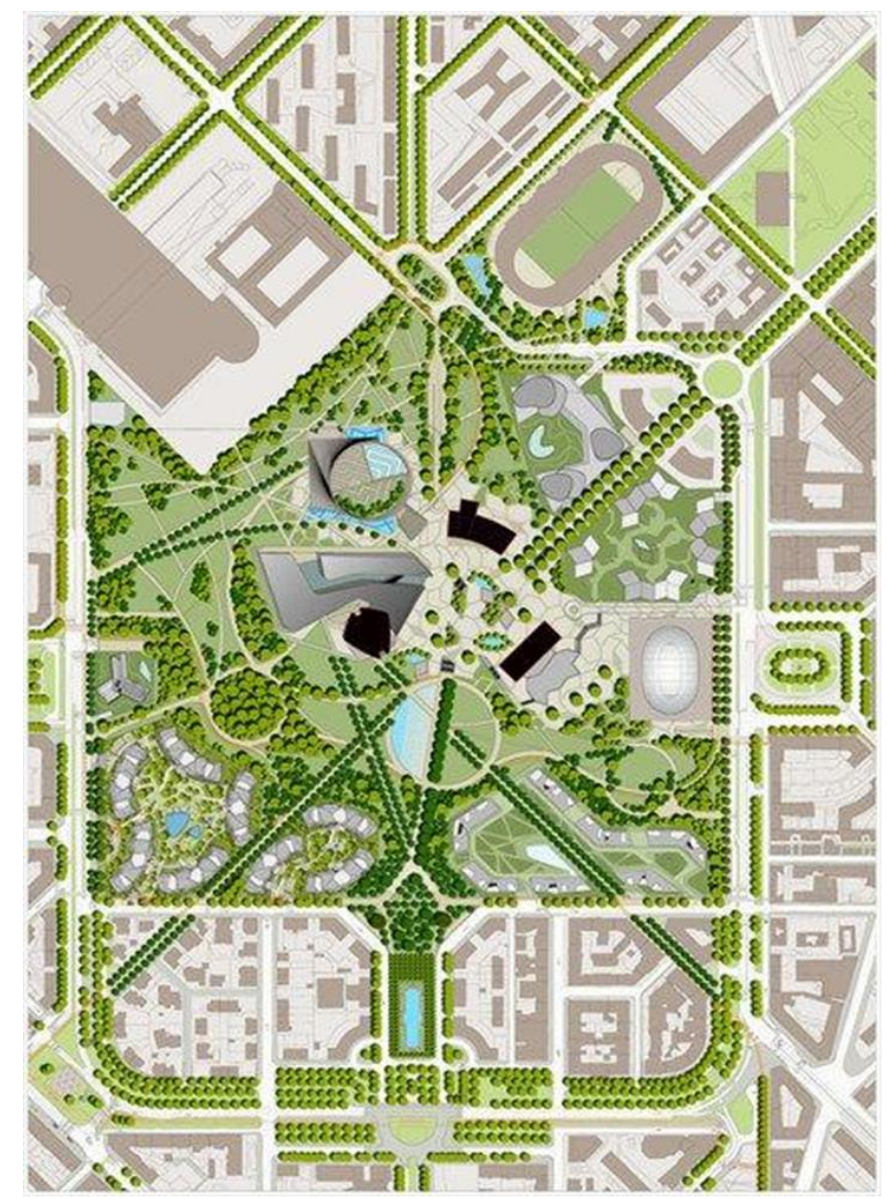

Fig. 2. Planning organization of the park territory CityLife. https://archi.ru/russia. 
The balconies are of different sizes, depending on the size of the apartments. It offers apartments of various layouts - from one-bedroom apartments to duplex penthouses.
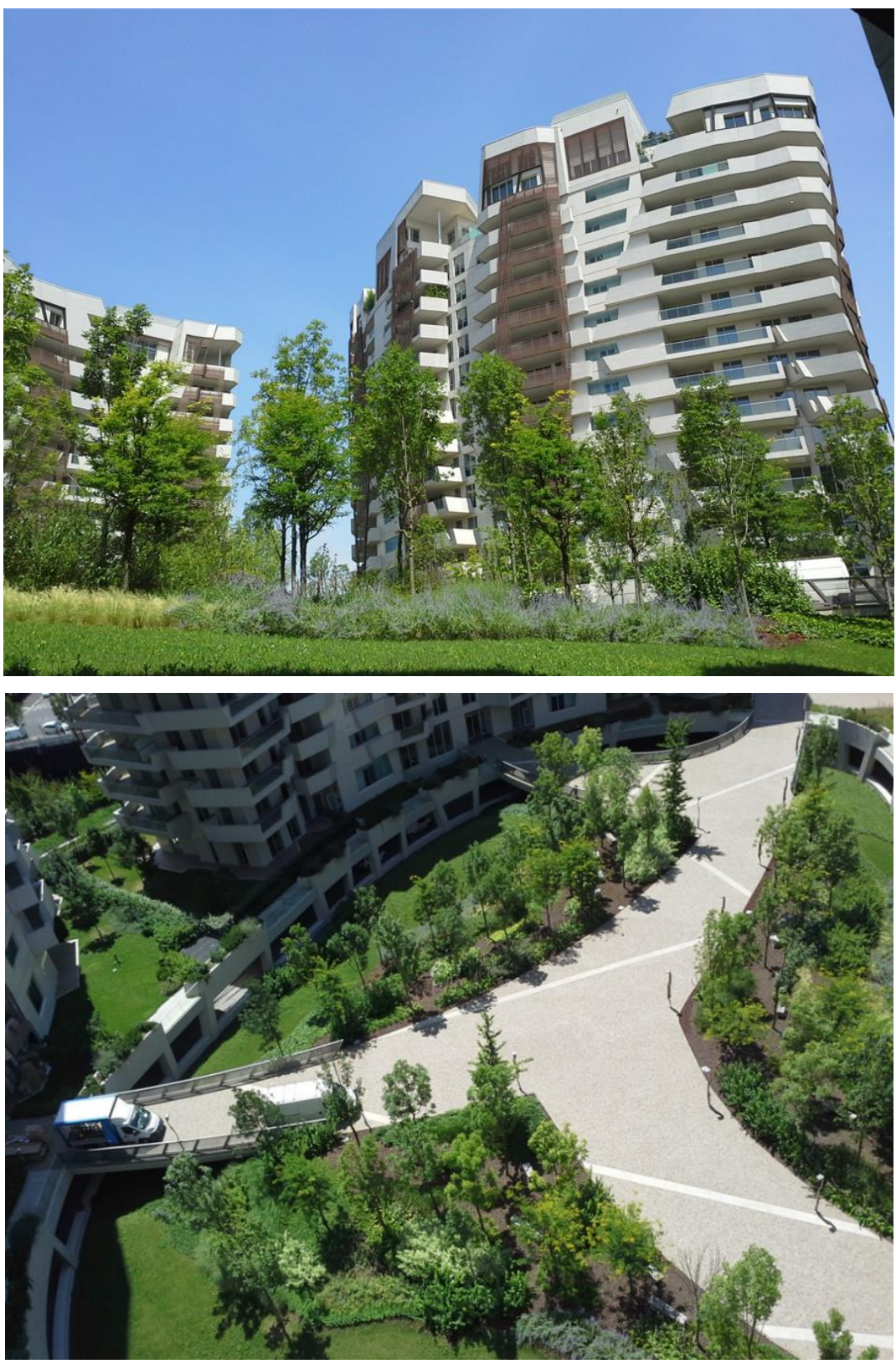

Fig. 3. Residential area in Milan. Arch. Daniel Libeskind. Photo by the author. Where: A. Residential area in Milan. Arch. Daniel Libeskind. Photo by the author; B. Top view of the inner courtyard of a residential area. 

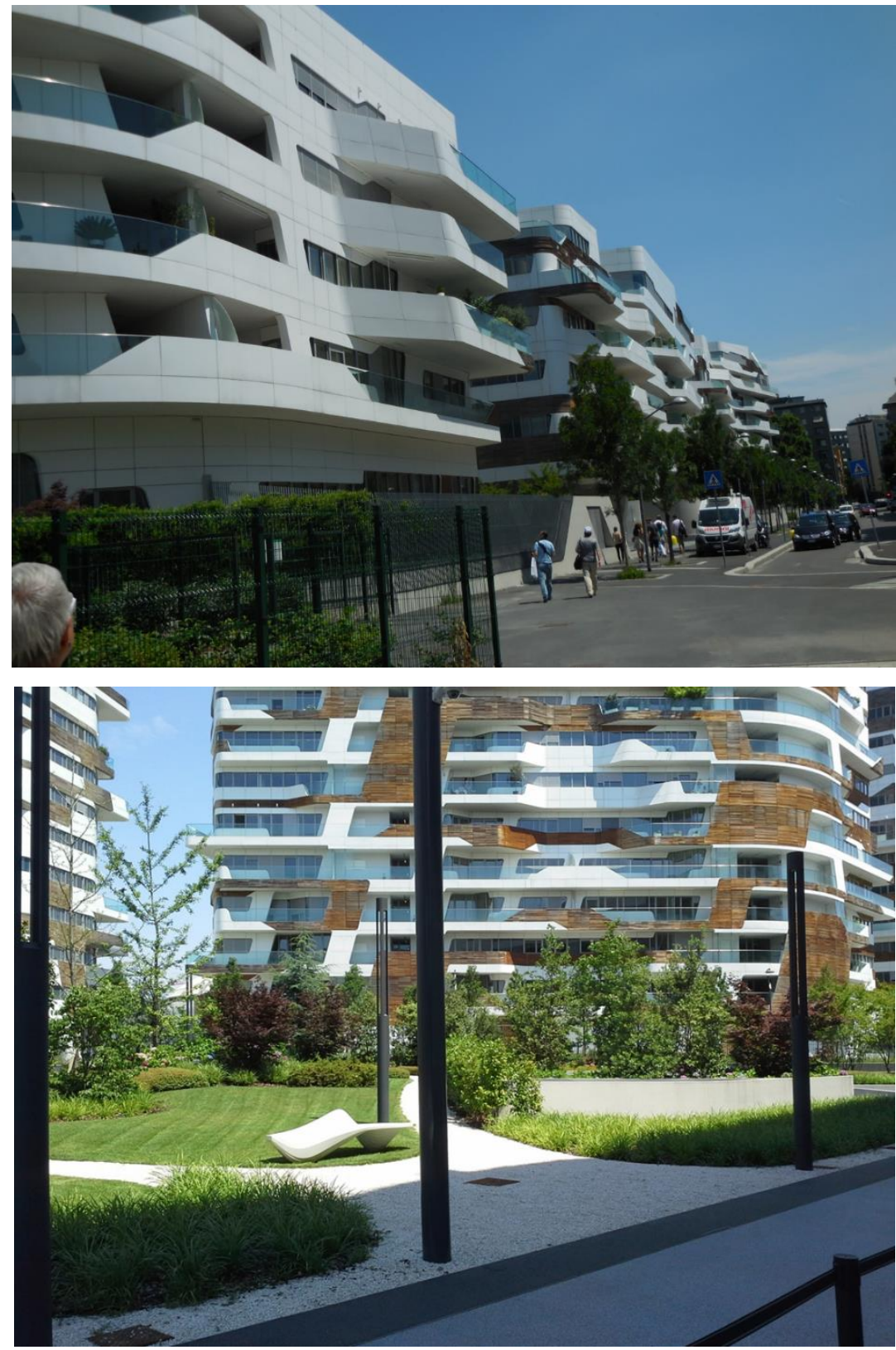

Fig. 4. Residential area in Milan. Arch. Zaha Hadid. Photo by the author. Where: A. View of the building from the adjacent street; B. View of the courtyard of the residential area, planning solution, design, equipment by Zaha Hadid.

The Zaha Hadid quarter is very plastic and resembles a multi-deck ship in shape. It includes seven perimeter buildings with heights ranging from 5 to 13 floors. All corners of buildings are rounded. The inclusion of wooden finishes in building facades, as in Libeskind's buildings, aims to soften the incorporation of modern buildings into the historical fabric of the city of Milan. The inner garden follows the smooth lines of the buildings and harmoniously complements the architecture of the buildings. In some areas, there are small 
hidden lawns intended for relaxation, separated by "green" walls. The design of lamps, benches, plastic paths was also made in the Hadid workshop.

A distinctive feature of the development of this project is the balconies designed in the form of ribbons encircling the buildings. Window shapes do not repeat each other. The apartments offer views of the city and park. There are also apartments with one or two bedrooms, as well as multi-level apartments. Residents enter the apartments through spacious lobbies with large windows overlooking the inner garden. The furniture in the lobbies is designed by the Hadid workshop and meets the highest requirements.

\section{Output}

The world practice of designing large urban formations shows that along with the sometimes uncontrolled urbanization of territories, there is a tendency to transform urban objects of various functional purposes in the central zones of the city. The project for the reconstruction of the territories is carried out on the basis of a comprehensive urban planning analysis, including the methods of historical and architectural research.

As domestic and foreign experience shows, the transformation of territories can have different directions and methods. Among the features of the transformations of urban objects, the process of integrating nature into the urban environment and the revival of the structured role of open spaces should be noted. But, at the same time, we are not talking about the preservation of nature in its natural manifestation. It is about organizing new elements of nature at objects and giving them qualities and properties corresponding to the level of the XXI century.

One of the tasks of transforming urban objects is to pursue a policy of sustainable development, which means the creation of favorable environmental conditions on their territory, the preservation of the material and spiritual culture of the place, the use of new energy efficient technologies in buildings, the use of circulating water supply systems for facilities, etc.

\section{References}

1. S. Sheina, A. Fedorovskaya, K. Yudina, Smart City: Comfortable Living Environment, 7 (2018) DOI: 10.1088/1757-899X/463/3/032095

2. D.V. Chebotarev, IOP Conf. Ser.: Mater. Sci. Eng. 1083, 012021 (2021) https://iopscience.iop.org/article/10.1088/1757-899X/1083/1/012021

3. A. Vorobyeva, Materials Science Forum 931, 856-861 https://doi.org/10.4028/www.scientific.net/MSF.931.856

4. A.P. Lapina, A.V. Saybel, M.V. Rozen, S.B. Yazyeva, Materials Science Forum 931, 722-726 (2018) https://doi.org/10.4028/www.scientific.net/MSF.931.722

5. A.M. Vorobeva, IOP Conference Series: Materials Science and Engineering 913, 032004 (2020) https://www.scopus.com/inward/record.uri

6. Y. Gorgorova, City brands: Identity in the urban environment (2019) DOI: 10.1088/1757-899X/698/3/033030

7. T. Berdnik, Experience in architectural renovation of the cultural objects and the monuments of historical heritage (2020) https://iopscience.iop.org/article/10.1088/1757-899X/913/3/032008

8. B.C. Meskhi, M.G. Evenko, A.M. Vorobeva, IOP Conference Se-ries: Materials Science and Engineering (2020) https://iopscience.iop.org/journal/1757-899X 
9. A.M. Vorobeva, Yu.Ya. Dvornikov, IOP Conference Series: Materials Science and Engineering 913, 032010 (2020) https://iopscience.iop.org/article/10.1088/1757$899 X / 913 / 3 / 032010$

10. I.V. Kaschina, A.N. Nesterova, Materials Science Forum 931 MSF, 817-821 (2018) https://doi.org/10.4028/www.scientific.net/MSF.931.817

11. S.G. Sheina, S.A. Tikhomirov, E.N. Minenko, International Journal of Applied Engineering Research 10(12), 31389-31402 https://www.scopus.com/inward/record.url?eid=2-s2.084937867140\&partnerID=40\&md5=5be9238f8031f258040a59acf1 8545e9

12. I. Mayatskaya, B. Yazyev, S. Yazyeva, P. Kulinich, MATEC Web of Conferences 106 (2017) DOI: 10.1051/matecconf/201710601031

13. S.B. Yazyeva, I.A. Mayatskaya, I.V. Kashina, A.N. Nesterova, IOP Conference Series: Materials Science and Engineering 698(3), 033046 (2019) DOI: 10.1088/1757899X/698/3/033046

14. L.V. Karaseva, Materials Science Forum 931, 759-764 (2018) 